\title{
Analysis of Beetroot Bulbs (Beta vulgaris) from Selected Geographical Regions in Kenya: Essential Nutritional Elements Contents
}

\author{
Grace Ndunge $^{1, ~ *}$, David Njoroge Kariuki ${ }^{2}$, Michael Josiah Mangala ${ }^{1}$, Michael James Gatari ${ }^{1}$ \\ ${ }^{1}$ Institute of Nuclear Science and Technology, University of Nairobi, Nairobi, Kenya \\ ${ }^{2}$ Department of Chemistry, University of Nairobi, Nairobi, Kenya
}

Email address:

grace.ndunge0@gmail.com (G. Ndunge)

${ }^{*}$ Corresponding author

To cite this article:

Grace Ndunge, David Njoroge Kariuki, Michael Josiah Mangala, Michael James Gatari. Analysis of Beetroot Bulbs (Beta vulgaris) from Selected Geographical Regions in Kenya: Essential Nutritional Elements Contents. Journal of Food and Nutrition Sciences.

Vol. 8, No. 4, 2020, pp. 112-116. doi: 10.11648/j.jfns.20200804.17

Received: July 21, 2020; Accepted: August 4, 2020; Published: August 13, 2020

\begin{abstract}
In Kenya, beetroot bulbs are occasionally used as a blend in fruit juices and salads, as a livestock feed and for treatment of diseases. Analysis of essential elements in beetroot bulbs was performed using Energy Dispersive X-ray fluorescence (EDXRF) in order to determine the nutritional content of the bulbs. The beetroot bulbs were sampled from five different geographical regions in Kenya; Karatina, Gilgil, Naivasha, Joska and Kisumu. The results of the concentrations of the essential elements had a range of: $10000 \mathrm{mg} \mathrm{kg}$ to $61000 \mathrm{mg} \mathrm{kg}^{-1}$ for potassium, $500 \mathrm{mg} \mathrm{kg}^{-1}$ to $4500 \mathrm{mg} \mathrm{kg}^{-1}$ for calcium, $15.0 \mathrm{mg} \mathrm{kg}^{-1}$ to $230 \mathrm{mg} \mathrm{kg}^{-1}$ for manganese, $24.0 \mathrm{mg} \mathrm{kg}^{-1}$ to $770 \mathrm{mg} \mathrm{kg}^{-1}$ for iron and $16.0 \mathrm{mg} \mathrm{kg}^{-1}$ to $680 \mathrm{mg} \mathrm{kg}^{-1}$ for zinc. In general, the trend in the concentrations of the essential elements was $\mathrm{K}>\mathrm{Ca}>\mathrm{Fe}>\mathrm{Mn}>\mathrm{Zn}$. Karatina samples registered the highest concentrations for all the elements of interest in this study. The results of analysis of variance (ANOVA) for all the five sampled regions show that there is a significant difference in the $\mathrm{Ca}, \mathrm{Fe}$ and $\mathrm{Mn}$ concentration levels. Beetroots were found to contain sufficient amounts of the essential elements, therefore, are a suitable vegetable source of essential elements of $\mathrm{K}, \mathrm{Ca}$, $\mathrm{Mn}, \mathrm{Fe}$ and $\mathrm{Zn}$ and can be used as an immune system booster. This study is supportive to the Government's efforts of improving health care and in the fight against "hidden hunger-malnutrition" in the country.
\end{abstract}

Keywords: Kenyan Beetroot Bulbs (Beta vulgaris), Energy Dispersive X-ray Fluorescence, Essential Nutritional Element Content

\section{Introduction}

Beetroot bulb is the taproot part of a beet plant which is among one of the several cultivated varieties of Beta Vulgaris. The usage of beets dates back from the third millennium BC as evidenced by Neolithic site of Aartswoud in the Netherlands and in the Saqqara pyramid at Thebes, Egypt [1]. In Kenya, beetroot is among the horticultural export products to the European Union. The total horticultural export as of 1990 was 125.1 metric tons with a value of USD 133.4 million [2].

Various health benefits are associated with beetroots; reduce blood pressure in hypertensive patients, and in reducing instances of cardiovascular diseases [3]. Sports endurance performance has also been found to improve with dietary nitrate supplementation that is found in beetroots [4].

Malnutrition cases and nutritional related diseases have been on the rise in Kenya. Nearly 73,000 children and 40,000 pregnant and nursing women in Kenya are severely malnourished and at risk of dying from drought-related hunger [5]. Common sources of essential minerals and vitamins to mitigate malnutrition are vegetables including beetroots.

In Kenya, beetroot is not a popular crop for consumption as it's taste and deep colour may have led to a bias against it. It is therefore crucial to have information on the nutritional value of beetroot bulbs since there are no studies conducted on essential elemental content of beetroots in Kenya. 


\section{Materials and Methods}

\subsection{Samples}

The samples consisted of thirty-four (34) beetroot bulbs sampled from different geographical regions in Kenya. Out of the thirty-four bulbs sampled, twelve (12) were from Karatina, nine (9) from Gilgil, seven (7) from Naivasha, four (4) from Joska and two (2) from Kisumu. Carrot and potato bulbs were also collected for comparison purposes. The soil types for Karatina, Gilgil, Kisumu, Joska and Giligil are clay soil, red volcanic, black cotton, loam and red volcanic, respectively.

\subsection{Instruments}

The spectrometers used in this study were Rigaku NEX CG bench top EDXRF and the AMPTEK EXP-1 EDXRF. The NEX CG is equipped with five secondary targets; RX9, Cu, $\mathrm{Mo}, \mathrm{Si}$ and $\mathrm{Al}$, that measure elements from $\mathrm{Na}$ - U. For improved accuracies on elemental analysis, a specialized light element optimization (LEO) secondary target is also available. A high performance SDD (Silicon Drift Detector), is utilized to realize high analytical precision and accuracy [6]. The AMPTEK EXP-1 EDXRF constitutes the X-ray SDD detector and its preamplifier. The PX4 constitutes three main parts: shaping amplifier, multichannel analyser and power supply. The Mini-X is an X-ray tube system that constitutes a 40 $\mathrm{kV} / 100 \mu \mathrm{A}$ power supply, X-ray Mo tube, USB provision for communication between computer and electronics [7].

\subsection{Sample Preparation Procedure}

All the samples were washed in double distilled water to remove soil and any foreign particles. The samples were sliced into thin slices then dried in the oven at $60^{\circ} \mathrm{C}$ for 56 hours to constant weight. After drying, the samples were ground into fine powder using a grinder then sieved with a 75-micron sieve.

For each ground sample, an approximate mass of between 0.5 - 0.6 grams were weighed for making pellets for EDXRF analyses. This was placed between two stainless steel dies enclosed in a cylindrical stainless-steel chamber then pressed using the hydraulic press at $10 \mathrm{kPa}$ to make thin pellets that were $25 \mathrm{~mm}$ in diameter. Each pellet was accurately weighed, labelled and stored in a Petri dish ready for analysis. For each sample, three pellets were prepared for EDXRF analysis [8].

\section{Results and Discussion}

\subsection{Method Validation}

Table 1 shows the results of EDXRF analysis using Rigaku NEX CG bench top of certified reference Materials; Bowen Kale and Soil-5.

Table 1. Experimental and certified t-values for reference materials ( $\left.\mathrm{mg} \mathrm{kg}^{-1} ; n=3\right)$.

\begin{tabular}{|c|c|c|c|c|c|c|}
\hline \multirow{2}{*}{ Element } & \multicolumn{3}{|l|}{ Bowen kale } & \multicolumn{3}{|l|}{ Soil-5 (IAEA- Soil-5) } \\
\hline & Experimental values & Certified values & T-test & Experimental values & Certified values & T-test \\
\hline $\mathrm{Mn}$ & $23 \pm 3$ & $15 \pm 2$ & 2.5 & $1100 \pm 200$ & $850 \pm 37$ & 2.5 \\
\hline $\mathrm{Fe}$ & $130 \pm 5$ & $120 \pm 15$ & 2.5 & $51000 \pm 1051$ & $45000 \pm 1700$ & 2.5 \\
\hline $\mathrm{Zn}$ & $32.9 \pm 1.4$ & $32 \pm 3$ & 2.8 & $490 \pm 4$ & $370 \pm 84$ & 2.5 \\
\hline $\mathrm{Ca}$ & $42000 \pm 160$ & $41000 \pm 2200$ & 2.5 & $29300 \pm 125$ & $22000 \pm 110$ & 2.5 \\
\hline $\mathrm{K}$ & $24000 \pm 140$ & $24000 \pm 1500$ & 2.5 & $23700 \pm 228$ & $19000 \pm 990$ & 2.5 \\
\hline
\end{tabular}

It was observed that the results of the experimental values were within the range of the certified values for all the five essential elements. From the t-test distribution table.

$\mathrm{T}_{\text {tab }}(\alpha=0.05,2)=4.3$ whereas from the results obtained, $\mathrm{t}_{\text {calc }}$ was less than 4.3. In the $\mathrm{t}$-test, if $\mathrm{t}_{\text {calc }}<\mathrm{t}_{\mathrm{tab}}$, there is no significant difference between the experimental value and the certified values [9]. This showed that the method was suitable and thus the results were accurate and reliable. Similar findings have previously been indicated for Bowen Kale using EDXRF spectrometer [10].

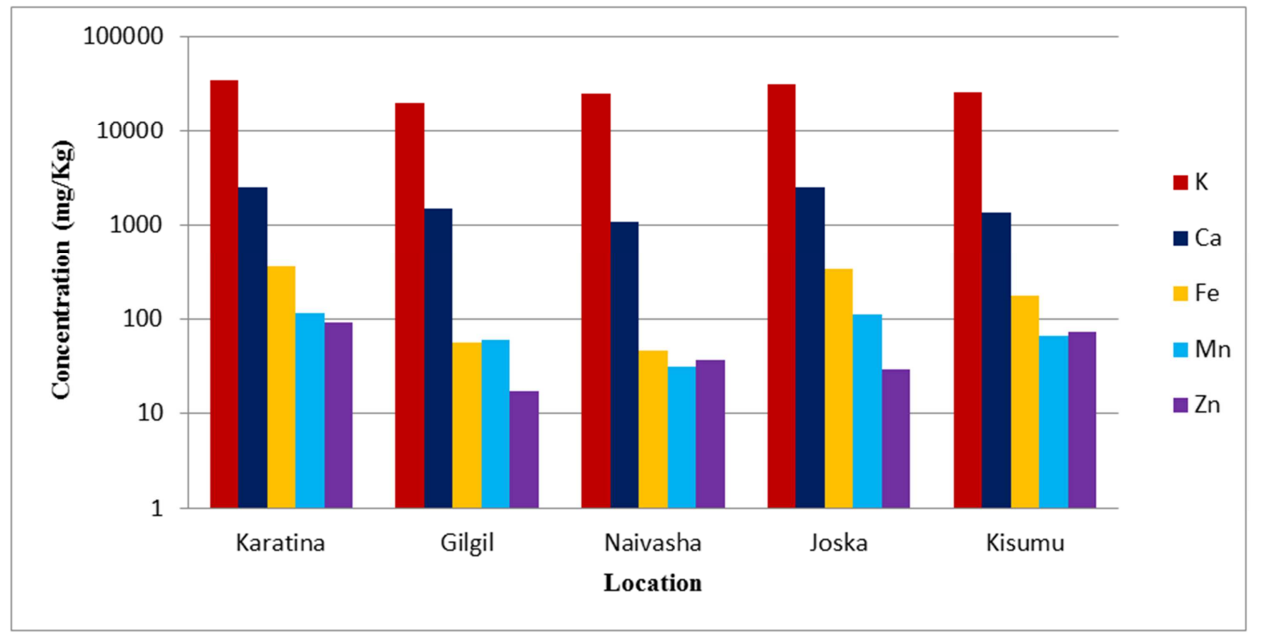

Figure 1. Trends in concentration of elements in all the sites. 


\subsection{Essential Element Concentration in Beetroot Samples}

The variations of elemental concentrations of the samples from different geographical regions are shown in figure 1. There is a uniform trend in the concentrations of $\mathrm{K}, \mathrm{Ca}$ and $\mathrm{Fe}$ in all the sampling sites, where $\mathrm{K}>\mathrm{Ca}>\mathrm{Fe}$. However, for $\mathrm{Mn}$ and $\mathrm{Zn}$, the trend of distribution in samples from Karatina, Naivasha and Kisumu is similar but significantly differs from those in Gilgil and Joska. The lowest concentration of $\mathrm{Zn}\left(15.5 \pm 1.2 \mathrm{mgkg}^{-1}-34.1 \pm 3.3 \mathrm{mgkg}^{-1}\right)$ was recorded in samples from Gilgil.

In general, all the elements have high concentrations in Karatina samples in comparison to the other regions. This can be attributed to the fact that, Karatina is found in the Kenyan highlands where the soils are deep, have high content of clay, porous and have excellent capacity to hold moisture compared to the other regions. Karatina experiences high annual rainfall approximately $1400 \mathrm{~mm}$ thus suitable for planting throughout the year [11].

\subsubsection{Potassium}

In general, the potassium mean concentration varies between $20000-31000 \mathrm{mgkg}^{-1}$. The results from analysis of variance for all the five sampled regions show that there is no significant difference in the means for potassium, since Fcalculated, $\mathrm{F}_{\text {calc }}=2.5<$ F-tabulated, $\mathrm{F}_{\text {tab }}=2.7$.

In the study, "Betalainic and nutritional profiles of pigment-enriched red beet root (Beta vulgaris L.)" [12] of dried extracts using Inductively Coupled Plasma Atomic Emission Spectroscopy, it was reported that potassium had an average concentration of $13730 \mathrm{mgkg}^{-1}$ which is less than values reported in this study.

The concentration of potassium from the study, "Nutritional value and economic feasibility of red beetroot (Beta vulgaris L. ssp. vulgaris Rote Kugel)" [13] from different production systems was reported to have an average of $33,766 \mathrm{mg} \mathrm{kg}^{-1}$, which is within the range of what was found in this study. Beetroot contains sufficient potassium levels to contribute to the daily dietary recommended intakes and thus can be recommended as a supplement [14].

\subsubsection{Calcium}

In this study, the results obtained for the analysis of beetroot samples for the calcium content show that there is a significant difference in the mean values, since $F_{\text {calc }}(6.5)>$ $\mathrm{F}_{\text {tab }}$ (2.7). The calcium mean concentrations vary between $1200-2800 \mathrm{mgkg}^{-1}$ in the sampled areas.

A study of trace elements in various vegetables that included carrots, broccoli, Muskmelon, spinach and tomatoes, showed that $\mathrm{Ca}$ concentrations were $2-3 \%, 1$ $2 \%, 3-5 \%, 1-2 \%$ and $1-3 \%$, respectively [ 15]. However, the calcium levels from this study were lower.

Another comparative study of the accumulation of calcium in different vegetables reported the following; lettuce 95213 $\pm 101 \mathrm{mgkg}^{-1}$, spinach $86606 \pm 102 \mathrm{mgkg}^{-1}$, hyacinth bean $84615 \pm 79 \mathrm{mgkg}^{-1}$ and cauliflower $80743 \pm 87 \mathrm{mgkg}^{-1}$ These values were all higher than those reported in this study [16].

\subsubsection{Manganese}

The manganese mean concentrations values vary between $36-130 \mathrm{mgkg}^{-1}$ in the samples. There is a significant difference in the manganese levels between the samples since $\mathrm{F}_{\text {calc }}(5.88)>\mathrm{F}_{\text {tab }}(2.7)$.

Manganese levels in some sampled vegetables, Amaranthus dubius, Amaranthus hybridus, Amaranthus spinosus, Asystasia gangetica, Cleome monophylla and Oxygonum sinuatum, reported the concentrations as ranging from $4 \mathrm{mg} / 100 \mathrm{~g}-82 \mathrm{mg} / 100 \mathrm{~g}$ [17].

The concentration of $\mathrm{Mn}$ in Cleome gynandra (spider plant) and Beta vulgaris L, aleafy vegetable known as chard or spinach beet, found that Beta vulgaris had levels 1.5 times greater than those found in Cleome gynandra. However, manganese levels reported in this study were higher, in general [18].

In a study carried out in Finland to analyze changes in the mineral and trace element contents of cereals, fruits and vegetables, it was reported that the concentration of manganese in different root vegetables were; potato 0.7 $\mathrm{mg} / 100 \mathrm{~g}$, organic carrot $1.2 \mathrm{mg} / 100 \mathrm{~g}$, beetroot $3 \mathrm{mg} / 100 \mathrm{~g}$, parsnip $1 \mathrm{mg} / 100 \mathrm{~g}$, celery root $1.5 \mathrm{mg} / 100 \mathrm{~g}$, turnip $1 \mathrm{mg} / 100 \mathrm{~g}$, swede $1.1 \mathrm{mg} / 100 \mathrm{~g}$, radish $1 \mathrm{mg} / 100 \mathrm{~g}$ and Jerusalem artichoke $0.2 \mathrm{mg} / 100 \mathrm{~g}$ [19]

In addition, other studies indicate that, the manganese levels were $30-60 \mathrm{mgkg}^{-1}, 25-150 \mathrm{mgkg}^{-1}, 20-100 \mathrm{mgkg}^{-1}$, 25-200 $\mathrm{mgkg}^{-1}$ and $25-200 \mathrm{mgkg}^{-1}$ for carrots, broccoli, Muskmelon, spinach and tomatoes, respectively. The manganese levels in this study were comparable and within the ranges [15].

The daily recommended intake for manganese for adults is 2-5 mg/day and 2-3 mg/day for children and beetroot is a suitable supplement [14].

\subsubsection{Iron}

There is a significant difference in the mean values for iron concentration, since $F_{\text {calc }}(14.22)>F_{\text {tab }}$ (2.7), following ANOVA analyses of the samples.

In this study, the mean iron content in beetroot samples range between 53 - $420 \mathrm{mgkg}^{-1}$, are higher than those reported in a study done in Uganda on iron and zinc content of selected foods in the diet of school children in Kumi District, East of Uganda, where they reported a mean of $50 \mathrm{mgkg}^{-1}$ in cassava, $140 \mathrm{mgkg}^{-1}$ in Irish potatoes and $56 \mathrm{mgkg}^{-1}$ in sweet potatoes [20].

Other studies have determined the mean iron content for roots to be $225 \mathrm{mgkg}^{-1}, 74.3 \mathrm{mgkg}^{-1}$ for barks, $195.4 \mathrm{mgkg}^{-1}$ for fruits and $333 \mathrm{mgkg}^{-1}$ for seeds, in plant samples and mean concentration of $71 \mu \mathrm{gg}^{-1}-280 \mu \mathrm{gg}^{-1}$ in beans from Cali, Colombia [21-22]. The concentrations of iron in different root vegetables are reported as; potato $3.4 \mathrm{mg} / 100 \mathrm{~g}$, organic carrot $3.4 \mathrm{mg} / 100 \mathrm{~g}$, beetroot $2.9 \mathrm{mg} / 100 \mathrm{~g}$, parsnip 3 $\mathrm{mg} / 100 \mathrm{~g}$, celery root $5.5 \mathrm{mg} / 100 \mathrm{~g}$, turnip $4 \mathrm{mg} / 100 \mathrm{~g}$, Swede $3.4 \mathrm{mg} / 100 \mathrm{~g}$, radish $6.5 \mathrm{mg} / 100 \mathrm{~g}$ and Jerusalem artichoke $1.8 \mathrm{mg} / 100 \mathrm{~g}$. These concentrations are all lower than those reported for beetroot in this study [19]. 
Iron is an essential nutrient in the body that plays an important role in transporting oxygen and carbon dioxide in the blood, preventing and treating anaemia, reducing heart failure and improving thinking and memory [23]. The dietary requirement of iron varies with age and sex. Boys and girls need the same amount of iron, about $10 \mathrm{mg} /$ day from ages 4 to 8 , and $8 \mathrm{mg} /$ day from ages 9 to 13 . Women need more iron, $18 \mathrm{mg}$ of iron per day from ages 19 to 50 because they lose blood each month during their menstrual periods, while men of the same age require $8 \mathrm{mg}$ /day [24]. In general, beetroot is a good source of iron for daily dietary intake.

\subsubsection{Zinc}

The results of zinc concentration levels vary between 14.0 $\mathrm{mgkg}^{-1}$ to $680 \mathrm{mgkg}^{-1}$ in all the beetroot samples, sampled in this study.

The ANOVA results show that there is no significant difference in the means since $F_{\text {calc }}(1.13)<F_{\text {tab }}(2.7)$.

In the evaluation of black tea, for mineral content, the zinc concentrations range between $0.2-1.5 \mathrm{mgkg}^{-1}$ [25]. A study conducted on vegetables and fruits cultivated around the surroundings of Tummalapalle Uranium mining site reported zinc concentration of $4.1 \pm 0.8 \mathrm{mgkg}^{-1}$ for tomatoes, $8.5 \pm 6.5$ $\mathrm{mgkg}^{-1}$ for green chilli, $5.2 \pm 0.8 \mathrm{mgkg}^{-1}$ for bitter gourd,
$4.5 \pm 2.9 \mathrm{mgkg}^{-1}$ for bananas, $7.3 \pm 5.1 \mathrm{mgkg}^{-1}$ for papaya and $9.2 \pm 4.2 \mathrm{mgkg}^{-1}$ for melons. These concentrations are low, when compared to those obtained for beetroot samples in this study [26]. However, the zinc levels in Amaranthus dubius, Amaranthus hybridus, Amaranthus spinosus, Asystasia gangetica, Cleome monophylla and Oxygonum sinuatum, are reported as ranging from $5 \mathrm{mg} / 100 \mathrm{~g}-56 \mathrm{mg} / 100 \mathrm{~g}$, are higher than the zinc concentration levels in beetroot reported in this study [18].

The concentration of zinc in different root vegetables elsewhere, are reported as; potato $1 \mathrm{mg} / 100 \mathrm{~g}$, organic carrot $2.1 \mathrm{mg} / 100 \mathrm{~g}$, beetroot $1.6 \mathrm{mg} / 100 \mathrm{~g}$, parsnip $2.1 \mathrm{mg} / 100 \mathrm{~g}$, celery root $3.7 \mathrm{mg} / 100 \mathrm{~g}$, turnip $2.4 \mathrm{mg} / 100 \mathrm{~g}$, swede 1.9 $\mathrm{mg} / 100 \mathrm{~g}$, radish $3.1 \mathrm{mg} / 100 \mathrm{~g}$ and Jerusalem artichoke 1.4 $\mathrm{mg} / 100 \mathrm{~g}$ [19]. The daily dietary requirement for zinc is $4.2-$ $14 \mathrm{mg} /$ day [14].

\subsection{Comparison of Beetroot, Moringa (M. oleifera), Potatoes and Carrots}

Table 2 shows the results of concentration levels of trace elements of interest in this study, for potatoes, moringa and carrots and beetroot for comparison.

Table 2. Concentration of Different Vegetables in $\mathrm{mg} \mathrm{Kg}^{-1}$.

\begin{tabular}{llllll}
\hline Type & Mn & Zn & Fe & Ca & K \\
\hline Beetroot & $90 \pm 15$ & $64 \pm 8$ & $134 \pm 1$ & $230 \pm 27$ & $2100 \pm 250$ \\
Potato & $15 \pm 2$ & $24 \pm 1$ & $53 \pm 3$ & $420 \pm 28$ & $2800 \pm 1600$ \\
Moringa & $89 \pm 5$ & $31 \pm 3$ & $370 \pm 17$ & $19000 \pm 110$ \\
Carrot & $29 \pm 5$ & $140 \pm 4$ & $6800 \pm 440$ & $24050 \pm 140$ \\
\hline
\end{tabular}

The concentrations levels for all the elements in beetroots are high, except calcium, where moringa and carrots has eight times and three times higher, respectively. In addition, the concentration of iron in moringa samples is higher than that of beetroot. Thus, is a good source of potassium, calcium, manganese, iron and zinc.

\section{Conclusion}

Cases of malnutrition and nutritional related diseases have been on the rise in Kenya, thus bringing forth the need for research to be carried out on assessing the nutritional value of different vegetables, fruits and food crops in general that constitute a diet.

This study determined the levels and variations of essential elements in beetroots sampled from Karatina, Gilgil, Naivasha, Joska-Machakos and Kisumu. The elemental concentrations were measured using Energy Dispersive Xray Fluorescence spectrometer.

The results of the concentrations of the essential elements had a range of: $10000 \mathrm{mg} \mathrm{kg}{ }^{-1}$ to $61000 \mathrm{mg} \mathrm{kg}^{-1}$ for potassium, $500 \mathrm{mg} \mathrm{kg}^{-1}$ to $4500 \mathrm{mg} \mathrm{kg}^{-1}$ for calcium, $15.0 \mathrm{mg}$ $\mathrm{kg}^{-1}$ to $230 \mathrm{mg} \mathrm{kg}^{-1}$ for manganese, $24.0 \mathrm{mg} \mathrm{kg}^{-1}$ to $770 \mathrm{mg}$ $\mathrm{kg}^{-1}$ for iron and $16.0 \mathrm{mg} \mathrm{kg}$ to $680 \mathrm{mg} \mathrm{kg}^{-1}$ for zinc. In general, the trend in the concentrations of the essential elements was $\mathrm{K}>\mathrm{Ca}>\mathrm{Fe}>\mathrm{Mn}>\mathrm{Zn}$. Karatina samples registered the highest concentrations for all the elements of interest in this study.

In general, the concentrations of essential elements in beetroots are higher than those found in most commonly consumed tubers and leafy vegetables. Beetroots were found to contain sufficient amounts of the essential elements, therefore, are a suitable vegetable source of essential elements and can be used as an immune system booster.

\section{Acknowledgements}

I am thankful to the University of Nairobi for offering me the scholarship to do MSc studies in Nuclear Science. I also appreciate the support of laboratory staff; Simion Bartilol, Chief Technologist, Institute of Nuclear Science and Technology, Justus. Okonda, Department of Physics, J. W. Macharia and E. Mwangi, Department of Chemistry, all from the University of Nairobi for their assistance in carrying out laboratory analysis for this study.

\section{References}

[1] Winner, C. (1993). History of the crop. In D. A. Cooke \& R. K. Scott (Eds.), The Sugar Beet Crop, World Crop Series (pp. 1-35). Dordrecht: Springer Netherlands. Retrieved May 7, 2019, from https://doi.org/10.1007/978-94-009-0373-9_1 
[2] Nyangweso, P. M., \& Odhiambo, M. O. (2004). Exporting Kenya's Horticultural Products: Challenges and Opportunities in The 21st Century (No. 9533). 2004 Inaugural Symposium, December 6-8, 2004, Nairobi, Kenya. African Association of Agricultural Economists (AAAE). Retrieved October 29, 2019, from https://ideas.repec.org/p/ags/aaaeke/9533.html

[3] George, T. W., Kaffa, N., \& Lovegrove, J. A. (2010). Beetroot juice consumption reduced blood pressure in normotensive individuals in an acute dose-response study. Proceedings of the Nutrition Society, 69 (OCE6). Retrieved October 4, 2018, from https://www.cambridge.org/core/journals/proceedingsof-the-nutrition-society/article/beetroot-juice-consumptionreduced-blood-pressure-in-normotensive-individuals-in-anacute-doseresponsestudy/A19D1E77261A0234C9D8EB6223EDFF4D

[4] Zafeiridis, A. (2014). The effects of dietary nitrate (beetroot juice) supplementation on exercise performance: A review. $\mathrm{Am}$ J Sports Sci, 2, 97-110.

[5] Kwena, A. M., Terlouw, D. J., Vlas, S. J. D., Phillips-Howard, P. A., Hawley, W. A., Friedman, J. F., Vulule, J. M., et al. (2003). Prevalence and Severity of Malnutrition In Pre-School Children In A Rural Area Of Western Kenya. The American Journal of Tropical Medicine and Hygiene, 68 (4_suppl), 9499.

[6] Moriyama, T. (2013). Analysis of environmental samples using an energy- dispersive X-ray fluorescence spectrometer NEX CG. The Rigaku Journal, 1 (29), 27-31.

[7] Redus, R., \& Huber, A. (2012). Figure of merit for spectrometers for EDXRF: Figure of merit for spectrometers for EDXRF. X-Ray Spectrometry, 41 (6), 401-409.

[8] TECDOC, I. (1997). Sampling, storage and sample preparation procedures for X-ray fluorescence analysis of environmental materials. IAEA.

[9] IAEA. (2003). Development and use of reference materials and quality control methods.

[10] Kipkemboi, C. B., MSc thesis (2009). Determination of Selected Essential Elements in Traditional Vegetables, Medicinal Plants, Fruits and Conventionally Grown Vegetables in Koibatek, Kenya. Kenyatta University.

[11] Muchena, F. N., \& Gachene, C. K. K. (1988). Soils of the Highland and Mountainous Areas of Kenya with Special Emphasis on Agricultural Soils. Mountain Research and Development, 8 (2/3), 183.

[12] Nemzer, B., et al., (2011). Betalainic and nutritional profiles of pigment-enriched red beet root (Beta vulgaris L.) dried extracts. Food Chemistry, 127 (1), 42-53.

[13] Straus, S., Franc, B., Matjaz, T., Ana, S., Crtomir, R., \& Martina, B. (2012). Nutritional value and economic feasibility of red beetroot (Beta vulgaris L. ssp. Vulgaris Rote Kugel) from different production systems. African Journal of Agricultural Research, 7 (42), 5653-5660.

[14] WHO. (2005). Vitamin and mineral requirements in human nutrition. Geneva: Geneva: World Health Organization. Retrieved September 20, 2018, from http://apps.who.int/iris/handle/10665/42716
[15] Campbell, C. R. (2000). Reference sufficiency ranges for plant analysis in the southern region of the united states. Retrieved from www.ncagr.gov/agronomi/saaesd/scsb394.pd

[16] Fahad, S. M., Islam, A. F. M. M., Ahmed, M., Uddin, N., Alam, M. R., Alam, M. F., Khalik, M. F., et al. (2015). Determination of Elemental Composition of Malabar spinach, Lettuce, Spinach, Hyacinth Bean, and Cauliflower Vegetables Using Proton Induced X-Ray Emission Technique at Savar Subdistrict in Bangladesh. BioMed Research International, 2015., Retrieved September 19, 2018, from https://www.ncbi.nlm.nih.gov/pmc/articles/PMC4503553/

[17] Odhav, B., Beekrum, S., Akula, U., \& Baijnath, H. (2007). Preliminary assessment of nutritional value of traditional leafy vegetables in KwaZulu-Natal, South Africa. Journal of Food Composition and Analysis, 20 (5), 430-435.

[18] Moyo, M., Amoo, S. O., Aremu, A. O., Gruz, J., Šubrtová, M., Jarošová, M., Tarkowski, P., et al. (2017). Determination of Mineral Constituents, Phytochemicals and Antioxidant Qualities of Cleome gynandra, Compared to Brassica oleracea and Beta vulgaris. Frontiers in Chemistry, 5. Retrieved September 19, 2018, from https://www.ncbi.nlm.nih.gov/pmc/articles/PMC5758552/

[19] Ekholm, P., Reinivuo, H., Mattila, P., Pakkala, H., Koponen, J., Happonen, A., Hellström, J., et al. (2007). Changes in the mineral and trace element contents of cereals, fruits and vegetables in Finland. Journal of Food Composition and Analysis, 20 (6), 487-495.

[20] Tidemann-Andersen, I., Acham, H., Maage, A., \& Malde, M. K. (2011). Iron and Zinc Content of Selected Foods in the Diet of Schoolchildren in Kumi District, East of Uganda: A CrossSectional Study. Nutrition Journal, 10, 81.

[21] Ancuceanu, R., Dinu, M., Hovaneţ, M. V., Anghel, A. I., Popescu, C. V., \& Negreş, S. (2015). A Survey of Plant Iron Content-A Semi-Systematic Review. Nutrients, 7 (12), 10320 .

[22] Petry, N., Boy, E., Wirth, J. P., \& Hurrell, R. F. (2015). Review: The Potential of the Common Bean (Phaseolus vulgaris) as a Vehicle for Iron Biofortification. Nutrients, 7 (2), 1144

[23] Watson, S. (2011). Iron: What You Need to Know. WebMD. Retrieved September 20, 2018, from https://www.webmd.com/vitamins-andsupplements/features/iron-supplements

[24] Beck, K. L., Conlon, C. A., Kruger, R., \& Coad, J. (2014). Dietary Determinants of and Possible Solutions to Iron Deficiency for Young Women Living in Industrialized Countries: A Review. Nutrients, 6 (9), 3747.

[25] Brzezicha-Cirocka, J., Grembecka, M., Ciesielski, T., Flaten, T. P., \& Szefer, P. (2017). Evaluation of Macro- and Microelement Levels in Black Tea in View of Its Geographical Origin. Biological Trace Element Research, 176 (2), 429.

[26] Basha, A. M., Yasovardhan, N., Satyanarayana, S. V., Reddy, G. V. S., \& Kumar, A. V. (2014). Trace metals in vegetables and fruits cultivated around the surroundings of Tummalapalle uranium mining site, Andhra Pradesh, India. Toxicology Reports, 1, 505. 